\title{
Energy-saving irrigation management
}

\author{
Sergey Andreev ${ }^{1, *}$, Vladimir Zaginaylov ${ }^{1}$, and Andris Matveev ${ }^{1}$ \\ ${ }^{1}$ FSBEI HE RGAU "Moscow Agricultural Academy named after KA Timiryazev", Institute of \\ Mechanics and Energy named after VP Goryachkina, 127550, Timiryazevskaya, 49, Russia
}

\begin{abstract}
A significant part of the water resources used in agricultural production comes for irrigation. Due to the strong dependence of soil moisture on weather factors, the irrigation process must be carefully managed. To date, irrigation management is mainly carried out either as a function of soil moisture or according to a predetermined program. The article shows that both methods of management are imperfect since they can lead to a violation of agrotechnical requirements and waste of water.

In order to improve the quality of irrigation and eliminate overspending of water resources, it was proposed to manage the water in a combined way. In this case, the formation of the control action occurs according to the results of the comparison of the controlled variable and disturbing influences with the reference values. The controlled value is the soil moisture, and as disturbing influences are considered the temperature and humidity of the air, atmospheric pressure, wind speed, precipitation. In addition, the proposed irrigation management method takes into account the forecast of the synoptic services on precipitation, their intensity and duration. To obtain information on the controlled value, as well as on disturbing influences, appropriate measuring devices are used, and information on the prediction of precipitation is delivered from a specialized server via the Internet.

Before starting to use the control method, the agrotechnical requirements, the type, age and vegetation period of the plants are determined and set. The inclusion of irrigation equipment is carried out in accordance with the program and shut down - depending on the magnitude of the control signal.
\end{abstract}

\section{Introduction}

Careful adherence to the water regime of plant development is a prerequisite for effective farming. Since soil moisture is highly dependent on a number of random factors, irrigation management must be flexible, continuous, and ensure accurate compliance with agrotechnical requirements during all growing periods. The method of irrigation control justified in the work takes into account a number of disturbing influences affecting soil moisture: precipitation, temperature and humidity, atmospheric pressure and wind speed. In addition, the method involves adjusting the control effect on the final soil moisture, as well as depending on the forecast of precipitation. The proposed method provides high accuracy of water supply and significant savings in water and energy resources.

${ }^{*}$ Corresponding author: energo-andreev@rgau-msha.ru 
The purpose of this work is to substantiate the method of irrigation management, combining the principles of forming the control action according to the program, as well as on the totality of disturbing factors and on the deviation of the controlled value, ensuring high accuracy of water input into the soil and eliminating unjustified expenditure of energy and water resources.

\section{Methods}

In this article, the method of theoretical analysis of the influence of external factors on soil moisture is described. The principle of induction is applied to disseminate the obtained data to substantiate the universal method of managing energy-resource-saving irrigation.

\section{Results and Discussion}

A necessary condition for effective farming is careful adherence to the water regime of plant development [1]. Under the conditions of modern agriculture, irrigation management is of paramount importance, since along with the need to fully meet agrotechnical requirements, the problem of saving water and energy resources $[3,4]$ arises with particular urgency.

The methods of irrigation management known today are based on the formation of a control action either in accordance with a pre-established program [5] or as a function of soil moisture [6]. Despite widespread use, program management is excessively rude and involves the operator in adjusting control commands for unplanned weather. Due to the high inertia of the dependence of soil moisture on disturbing influences, as well to the inertia of artificial moistening, the control method for deviation is characterized by a significant dynamic error [7] and allows the possibility of overruns of energy and water. A significant drawback of the known methods of irrigation management is the lack of consideration of the forecast, which in some cases contributes to the under-wetting of the soil or its over-wetting while overspending water and energy resources. For example, with a decrease in soil moisture to the minimum allowable value, the known methods suggest the inclusion of irrigation equipment $[8,9]$. However, it may be that heavy rain is expected in the irrigated area. The inclusion of irrigation equipment, in this case, is undesirable, as this may lead to unacceptable overwetting. Besides, the unjustified inclusion of irrigation equipment will cause excessive energy consumption, excessive water consumption, and additional wear and corrosion of structural elements.

In order to improve the quality of irrigation and achieve energy, resource conservation in its implementation, a new method for controlling the mode of water inflow into the soil was proposed, combining the principles of open and closed operation. The open principle provides for the inclusion of irrigation equipment in accordance with the program. At the same time, the duration of irrigation is established according to a closed principle, which includes taking into account a number of disturbing influences and the value of the controlled quantity. Herewith, the consideration of disturbing influences is basic in the normal mode, and the priority formation of the control action on deviation takes effect upon the occurrence of unplanned situations. In addition, the proposed method provides the possibility of adjusting the control when receiving information about the forecast.

In the proposed method, precipitation, temperature, humidity of the air, atmospheric pressure and wind speed are considered as disturbing effects. Influence of the precipitation on soil moisture does not need comments [10], and other factors can be justified by the following considerations.

The dehydration of the soil during the evaporation of moisture in the process of transition of water into a gaseous state, not accompanied by the decomposition of molecules into their 
constituent atoms. This process consists in the separation of particles from the soil surface into the environment. With increasing temperature, the change in the rate of evaporation of moisture is subject to two opposite trends. On the one hand, the elasticity of water vapor increases, on the other hand, its diffusion is facilitated. Steam elasticity prevents the separation of water particles from the soil surface. From a theoretical point of view, when the air is saturated with water vapor, evaporation should slow down. However, due to the presence of open space above the soil, no saturation occurs. From this, we can conclude that the humidity of the environment does not depend on the drainage of the soil. Evaporation of water will continue as the vapor from the subsoil layer diffuses into remote space or is carried away by the wind. As a result, there is only one tendency, according to which with the increase in air temperature in the subsurface space, the vapor diffusion coefficient changes, which determines the increase in the intensity of water evaporation. As an example, we can cite the well-known dependence of productive soil moisture in the metering layer when growing wheat in the period from the entrance to the tube to wax ripeness on temperature and precipitation intensity [11]:

$$
\Delta \mathrm{W}=-0,36 \mathrm{~T}+0,46 \mathrm{~m}-0,03 \mathrm{~W}+5,9
$$

where

$\Delta \mathrm{W}$ - the change in water reserves, $\mathrm{mm} /$ day;

$\mathrm{T}$ - the average daily air temperature, degrees $\mathrm{C}$;

$\mathrm{m}$ - amount of precipitation, $\mathrm{mm} /$ day

$\mathrm{W}$ - the initial amount of moisture in the soil, $\mathrm{mm}$.

The rate of evaporation of moisture significantly depends on the humidity of the air above the soil. With dry air, the humidity pressure from the side of the soil being dried increases, and the evaporation rate increases. At the same time, at high air humidity, the process of draining the soil slows down.

It is established that atmospheric pressure also affects the intensity of drainage of the soil. In accordance with the Dalton formula [12], the amount of moisture evaporated per unit time is calculated by the formula:

$$
P_{d}=\frac{A_{d} \cdot S_{d} \cdot\left(F_{d}-f_{d}\right)}{H}
$$

where $\quad A_{d}$ - coefficient taking into account the nature of the liquid, $\mathrm{g} \cdot \mathrm{m}^{2} / \mathrm{c}$; ;

$S_{d}$ - the soil surface interacting with air, $\mathrm{m}^{2}$;

$F_{d}-$ limiting elasticity of water vapor, $\mathrm{mm}$

$f_{d^{-}}$the actual elasticity of water vapor, $\mathrm{mm}$;

$\mathrm{H}$ - atmospheric pressure, $\mathrm{mm} \mathrm{Hg}$.

The increase in the intensity of evaporation with a decrease in atmospheric pressure is explained by the facilitation of the conditions for the separation of water molecules and their transition to a gaseous state. At the same time, the rate of flow of air (in natural conditions the wind) affects the rate of evaporation of moisture. This dependence can be described by the de Guin formula [13]:

where $\quad A_{d}-$ the air flow rate.

$$
v_{\text {air }}=\frac{A_{d} \cdot\left(F_{d}-0,88 f_{d}\right)}{u_{\text {air }}}
$$

When growing plants, soil moisture may reach the minimum allowable value, but due to low air temperature, its high humidity, high atmospheric pressure, or lack of wind, moisture will evaporate from the soil very slowly. At the same time, the irrigation equipment should be either switched off or switched on with a certain time delay, counting on a change in the weather. Otherwise, the over-moistening of the soil or the overrun of energy expended on the operation of the pumps will occur [14]. Similarly, if the soil moisture is at the maximum permissible value, the immediate shutdown of the irrigation equipment, accompanied by increased air temperature, its low humidity, low atmospheric pressure, and strong wind, will cause intense evaporation of moisture from the soil and it will dehydrate. As a result, the irrigation equipment must remain in the switched-on state for some time. 
Thus, to improve the efficiency of irrigation, traditional control operations need to be supplemented by measuring the temperature and humidity of the air, atmospheric pressure, and wind speed, as well as taking into account information on the forecast of precipitation [15]. At the same time, the frequency and intensity of irrigation should be correlated with agrotechnical requirements, and its duration - with the values of soil moisture, precipitation intensity, air temperature and humidity, as well as atmospheric pressure, wind speed and forecast of precipitation. The duration of irrigation should be increased with positive differences between the desired and actual values of the following parameters: soil moisture, precipitation intensity, air humidity and atmospheric pressure [16]. Conversely, the duration of irrigation should decrease with positive differences between the set and actual values of air temperature and wind speed [17]. In addition, the duration of irrigation should be reduced with a positive forecast of precipitation.

The functional diagram of the technical implementation of the energy-resource-saving irrigation management system is presented in Figure 1.

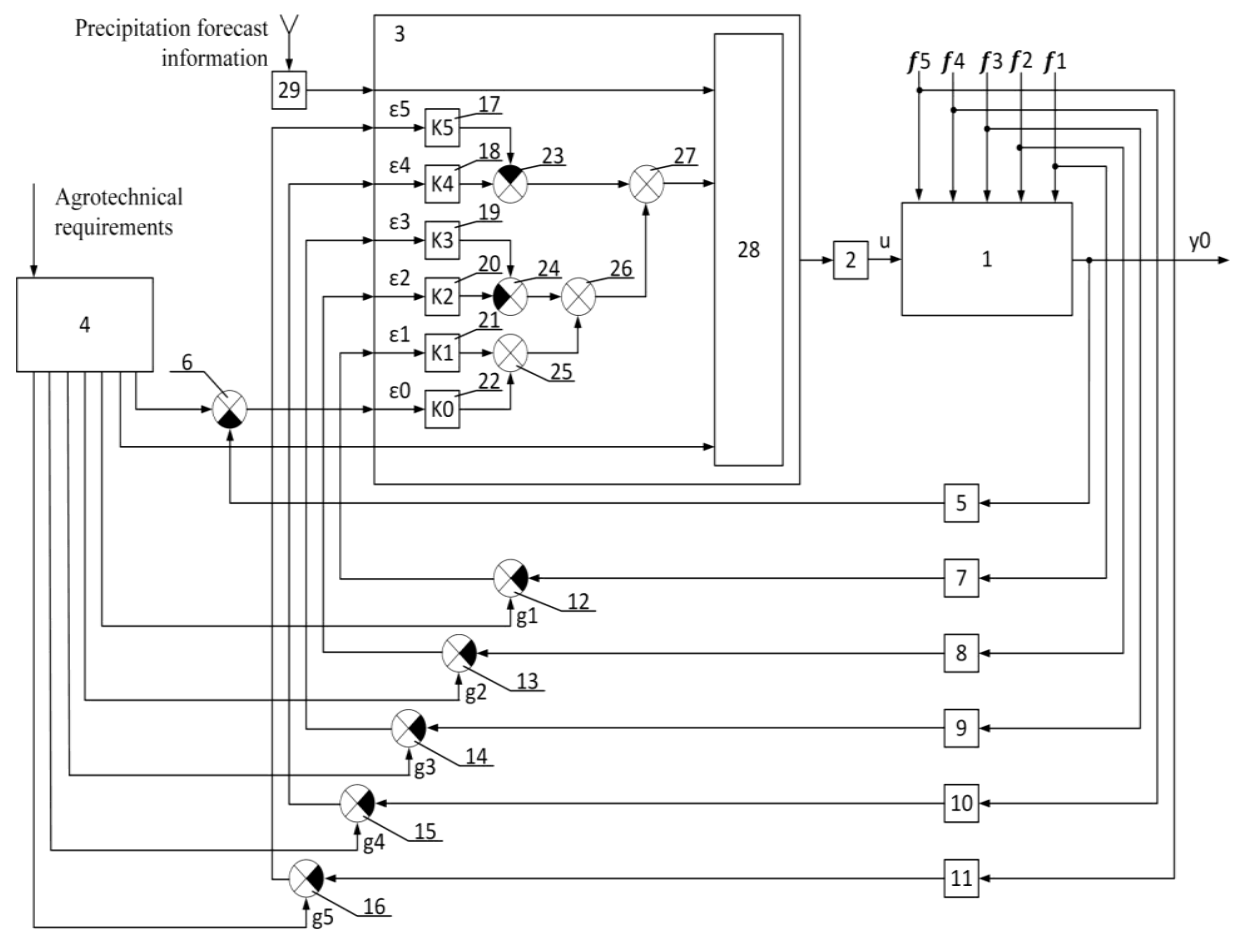

Fig. 1. Functional diagram of the energy-resource-saving irrigation management system

The irrigated area is a control object 1 , the state of which is characterized by a controlled quantity $y_{0}$ (humidity).

The control object is influenced by several disturbing influences characterized by precipitation intensity $\left(f_{1}\right)$, air temperature $\left(f_{2}\right)$, air humidity $\left(f_{3}\right)$, atmospheric pressure $\left(f_{4}\right)$, wind speed $\left(f_{5}\right)$. Irrigation is carried out by irrigation equipment - regulatory authority 2 . Regulator 3 turns on and off regulator 3. The aggregate of agrotechnical requirements is converted by block 4 of the task into the setting effect $g_{0}$, which is the required soil moisture. Soil moisture $y_{0}$ is measured by the perceiving element 5 , from the output of which the information signal is fed to the negative input of the adder 6 . The positive input of this adder is given by the specifying effect $g_{0}$ from the block 4 of the task. Here is the operation of 
comparing the input signals by subtracting: $\varepsilon_{0}=g_{0}-y_{0}$. The signal $\varepsilon_{0}$ indicates the presence of deviations of the actual soil moisture from the specified value.

When the deviation $\varepsilon_{0}$ exceeds the set threshold, the regulator 3 is triggered and the irrigation duration is adjusted, realizing the control principle "by deviation". To implement the "perturbation" control principle, five contours are introduced in the system, which provide for the formation of a control action according to the intensity of precipitation $f$, according to air temperature $f_{2}$, according to air humidity $f_{3}$, according to atmospheric pressure $f_{4}$ and wind speed $f_{5}$.

The "perturbation" control principle allows one to proactively change the control action $\mathrm{u}$, preventing deviation of soil moisture $y_{0}$. The perturbation control loops include perceiving elements $7,8,9,10$, and 11 , which are sensors of precipitation intensity $f_{1}$, air temperature $f_{2}$, humidity $f_{3}$, atmospheric pressure $f_{4}$ and wind speed $f_{5}$, respectively, as well as adders $12,13,14,15$, and 16. At the same time, the outputs of the sensing elements $7,8,9,10$, and 11 are connected to the negative inputs of the adders $12,13,14,15$, and 16; and the positive inputs there are connected $g_{1} . g_{2}, g_{3}, g_{4}$ and $g_{5}$. In the adders $12,13,14,15$ and 16 , the formation of the error signals of the disturbing influences takes place in accordance with the conditions: $\varepsilon_{1}=g_{1}-f_{1}, \varepsilon_{2}=g_{2}-f_{2}, \varepsilon_{3}=g_{3}-f_{3}, \varepsilon_{4}=g_{4}-f_{4}$ и $\varepsilon_{5}=g_{5}-f_{5}$.

Assuming the linear nature of the influence of each factor, the duration of irrigation can be determined by the expression:

$$
t=\varepsilon_{0} \cdot k_{0}+\varepsilon_{1} \cdot k_{1}-\varepsilon_{2} \cdot k_{2}+\varepsilon_{3} \cdot k_{3}+\varepsilon_{4} \cdot k_{4}-\varepsilon_{5} \cdot k_{5}
$$

Regulator 3 contains amplifiers 17, 18, 19, 20, 21 and 22, adders 23, 24, 25, 26 and 27, as well as a crucial block $28[18,19]$. The coefficients $k_{0}, k_{1}, k_{2}, k_{3}, k_{4}$ and $k_{5}$, characterize the significance of the deviations of each factor and are specified as transmission coefficients in the blocks of amplifiers 17, 18, 19, 20, 21 and 22. Algebraic summation products $\left(\varepsilon_{0}\right.$. $\left.k_{0}\right),\left(\varepsilon_{1} \cdot k_{1}\right),\left(\varepsilon_{2} \cdot k_{2}\right),\left(\varepsilon_{3} \cdot k_{3}\right),\left(\varepsilon_{4} \cdot k_{4}\right)$ and $\left(\varepsilon_{5} \cdot k_{5}\right)$ is performed using adders 23 , $24,25,26$ and 27.

Information on the forecast of precipitation is transmitted from meteorological services via communication lines, received by the receiving unit 29 and fed to the decision block 28 of the regulator 3 [20]. Upon receipt of a positive forecast, irrigation is canceled and regulator 2 is immediately turned off.

\section{Conclusions}

The proposed energy-saving method of irrigation control provides improved accuracy of water metering. This contributes to more accurate compliance with agrotechnical requirements when growing agricultural plants. When implementing the method increases the performance of the irrigation system due to the proactive adjustment of water supply depending on precipitation, temperature and humidity, atmospheric pressure and wind speed. The proposed method allows to eliminate the waste of energy and water, as well as to avoid unnecessary wear and tear of irrigation equipment.

\section{References}

1. N.S. Erkhov, N.I. Ilin, V.S. Misenev. Land reclamation, 2nd edition (Moscow, Agropromizdat, 1991)

2. O.A. Chernova, I.V. Mitrofanova, L.A. Dinh. Economics: Yesterday, Today and Tomorrow 7, No. 3B, 312-325 (2017)

3. Ya.E. Pulatov. Ecology and Construction 4, 21-26 (Kolomna, Research and Development Center for Ecology and Construction Limited Liability Company, 2017) 
4. V.V. Kundius. Environmental Engineering 3, 123-126 (Moscow, Russian State Agrarian University, Moscow Timiryazev Agricultural Academy, 2010)

5. L.V. Makotrina, A.A. Ievleva. News of universities. Investments. Building. Real Estate 2 (5), 86-94. (Irkutsk, Irkutsk National Research Technical University, 2013)

6. P.I. Kovalenko. Automation of land reclamation systems (Moscow, Kolos, 1983)

7. N.I. Kirilin. The theory of calculation of optimal automatic control systems. (Moscow, MGAU named after V.P. Goryachkina, 1999)

8. Yu.V. Egorov, S.S. Litvinov, V.I. Galitsky, R.D. Nurmetov. Method for automatic control of drip irrigation in a greenhouse and device for its implementation. Pat. 2216930 Rus. Fed.: IPC A 01 G 25/16 (2000.01), A 01 G 9/00 (2000.01), A 01 G 9/02 (2000.01) - 2001135084/13; declare 12/26/2001; publ. November 27, 2003. Bul. No. 33.

9. N.G. Chefonov, V.I. Korshunov, T.A. Chefonova. Method of control and monitoring by automated irrigation system. Cop. Cert.: № 1319803 USSR IPC A 01 G 25/16, A 01 G 27/00. 3907113 / 30-15; declare 06/05/1985; publ. 06/30/1987. Bul. No. 24.

10. N.S. Erkhov, N.I. Ilin, V.S. Misenev. Land reclamation, 2nd edition (Moscow, Agropromizdat, 1991)

11. A.M. Shulgin. Soil climate and its regulation (Leningrad, Hydrometeorological Publishing House, 1967)

12. S.P. Khromov, L.I. Mamontova. Meteorological dictionary, 3rd edition (Leningrad, Publishing house Gidrometeoizdat, 1974)

13. I.L. Knunyants. Chemical encyclopedic dictionary (Moscow, Soviet Encyclopedia, 1982)

14. E.I. Kuznetsova, E.N. Zakabunina, Yu.F. Spinich. Irrigated agriculture (Moscow, FGBOU VPO RNAZU, 2012)

15. S.A. Andreev, Yu.A. Sudnik, A.I. Matveev. Method of controlling irrigation. Pat. 2622695 Rus. Fed.: IPC A 01 G 25/16 - 2016100223; declare 01/11/2016; publ. 19.06.2017 Bul. N 17

16. S.V. Makarychev, N.I. Zaikova, V.Yu. Patrushev. Vestnik AGAU 2, 56-61 (2017)

17. N.A. Ivanova, I.V. Gurina, S.F. Shemet. Scientific journal of the Russian Research Institute of Land Reclamation Problems 4(16), 124-135 (2014)

18. A.V. Kuzmin, A.G. Skhirtladze. The theory of automatic control systems (Stary Oskol, TNT, 2017)

19. I.F. Borodin, S.A. Andreev. Automation of technological processes and automatic control systems (Moscow, Kolos, 2005)

20. W. Stallings. Data transfer, 4th edition (Saint Petersburg, House Peter, 2004) 